\title{
Effect of calcination on band gap for electrospun titania nanofibers heated in air-argon mixtures
}

\author{
H. Albetran ${ }^{\mathrm{a}, \mathrm{b}}$, B. H. O'Connor ${ }^{\mathrm{a}, \mathrm{c}}$, I. M. Low ${ }^{\mathrm{a}, *}$ \\ a Department of Imaging \& Applied Physics, Curtin University, GPO Box U1987, Perth, WA \\ 6845, Australia. \\ ${ }^{\mathrm{b}}$ Department of Basic Sciences, College of Education, University of Dammam, P. O. Box 2375, \\ Dammam 31451, Saudi Arabia. \\ ' John de Laeter Centre, Curtin University, GPO Box U1987, Perth, WA 6845, Australia. \\ *Corresponding author. Tel.: +61 892667544; fax: +61 892662377. \\ E-mail address: j.low@curtin.edu.au
}

\begin{abstract}
The relationship between the band gap in electrospun titania nanofibers at ambient temperature and the nature of the air-argon atmosphere in which the material has been heated nonisothermally to $900{ }^{\circ} \mathrm{C}$ was investigated by ultraviolet-visible absorption spectrometry at room temperature. The results for heating in different selected air-argon mixtures show that the UVregion band gap found in unheated as-spun amorphous nanofibers, $3.33 \mathrm{eV}$, may be shifted well into the visible region by calcining in the different air-argon mixtures. The band gap value found for heating in air, $3.09 \mathrm{eV}$, reduces systematically when the material is heated in an airargon mixture, with the gap in pure argon being $2.18 \mathrm{eV}$. The progressive lowering of the band gap is attributed to the development of crystallinity in the fibers as the material is calcined and the associated development of oxygen vacancies when heated in argon, and therefore to the formation of defect states below the conduction band.
\end{abstract}

Keywords: Titania nanofibers, Electrospinning, Oxygen vacancies, Band gap, Photocatalysis. 


\section{Introduction}

Titanium dioxide $\left(\mathrm{TiO}_{2}\right)$ or titania has received much attention as a photocatalytic and photovoltaic semiconductor because it is relatively inexpensive, eco-friendly and has long-term photostability [1-2]. It is a wide band gap semiconductor ceramic with an optical band gap for amorphous titania being in the range $3.30-3.5 \mathrm{eV}$ [3]. This value decreases for two common crystalline titania forms: crystalline anatase $(\sim 3.20 \mathrm{eV})$, and crystalline rutile $(\sim 3.02 \mathrm{eV})[4$, $5]$.

Although rutile has a smaller band gap than crystalline anatase, the latter is most favored because it has a higher photoactivity than crystalline rutile, whereas a mixture of crystalline anatase and rutile has been reported to exhibit superior photocatalytic ability [6-8]. Thus, many studies have been conducted on the photocatalytic activity of crystalline titania because crystallinity is an important parameter that influences band gap narrowing in titania. Titania powder which is used as a commercial photocatalytic material (Degussa, P25), may include small amounts of amorphous phase, a minor quantity of crystalline rutile, and more than $70 \%$ crystalline anatase [9]. Some studies have focused on photocatalytic activities and the band gap for amorphous titania or a mixture of amorphous and crystalline titania [3].

An optimum combination of titania phases with lower band gap can be synthesized by thermal treatment of amorphous titania, which transforms to crystalline anatase at relatively low temperature, and then the crystalline anatase transforms to crystalline rutile at higher temperature. The amorphous-to-crystalline transformation of electrospun titania nanofibers has been studied by the authors from room temperature to $900{ }^{\circ} \mathrm{C}$ in $100 \%$ air and $100 \%$ argon atmospheres [10]. After thermal treatment, a sample heated in $100 \%$ argon contains more crystalline content (anatase and rutile) than that heated in $100 \%$ air due to the influence of oxygen vacancies created under argon. To the best of the author's knowledge, the effect of 
degree of crystallinity on the titania band gap for a mixture of amorphous and crystalline titania has not been reported previously.

When chemically pure, titania must be exposed to ultraviolet (UV) radiation to become photo-active. Various treatments, such as an organic dye attachment, hydrogen plasma reduction, and extrinsic chemical doping $[11,12]$, have been investigated to reduce the band gap of titania in order to achieve photocatalytic activity under visible light (1.77-3.10 eV).

Impurity doping with various anions and cations has been used to create oxygen vacancies and thus modify the electronic structure to achieve visible light absorption [13-19]. A major disadvantage with chemical doping, however, is that dopant chemicals may be corrosive and pollute the environment (i.e., secondary pollution). A reduction of the band gap without chemical doping is, therefore, an attractive proposition.

The introduction of oxygen vacancies can result in $\mathrm{Ti}^{3+}$ states which may be used as intrinsic donors to narrow the band gap of titania such that they can act as n-type donors. The introduction of oxygen vacancy defects into non-doped titania can influence the photocatalytic behavior significantly. Here the defects act as recombination centers for photo-induced electron-hole pairs, thereby reducing the band gap and enabling photoactivity under visible light [20]. Oxygen vacancies have been created by annealing titania in hydrogen, argon, or in a vacuum [20-22]. The oxygen vacancy concentration increases with increase in calcination temperature in these atmospheres, whereas it remains constant in air.

Using titania in an electrospun nanofiber form is attractive for photocatalysis applications since titania nanofibers have a high ratio of surface area to volume, which increase the decomposition rate of air and water pollutants and this allows for photocatalytic reactions to occur more rapidly on the photocatalyst surface [23-30].

In this work, a novel strategy was used to create oxygen vacancies in a mixture of amorphous titania, crystalline anatase, and crystalline rutile in electrospun titania nanofibers to narrow the 
band gap. Amorphous titania nanofibers were synthesized by electrospinning, and their morphology and band gap were characterized before and after calcination in air-argon mixtures, using field emission scanning electron microscopy (FESEM), energy dispersive spectroscopy (EDS) and UV-visible spectrometry.

\section{Experimental procedures}

\subsection{Electrospun titania nanofiber synthesis}

Electrospun titania nanofibers were synthesized by a combination of sol-gel and electrospinning methods. A titania sol-gel solution was prepared by mixing titanium isopropoxide (IV), ethanol, and acetic acid in a fixed volume ratio of 3:3:1, and then $12 \mathrm{wt} \%$ polyvinylpyrrilidone (PVP) was dissolved in the solution. The titania sol-gel solution precursor was stirred ultrasonically before being loaded into a $10 \mathrm{ml}$ plastic syringe with a $25-\mathrm{G}$ stainless steel needle in the electrospinning experiment. The voltage setting was controlled using a high voltage power supply to maintain $25 \mathrm{kV}$ between the needle tip and an aluminum collector at $12 \mathrm{~cm}$. A syringe pump was used to control the titania sol-gel solution flow rate at $2 \mathrm{ml} / \mathrm{h} \mathrm{during}$ the electrospinning process [25].

\subsection{Heating protocol}

Electrospun titania nanofibers were heated non-isothermally from 25 to $900{ }^{\circ} \mathrm{C}$, at 10 ${ }^{\circ} \mathrm{C} / \mathrm{min}$ in air-argon mixtures using a TGA/DSC Mettler Toledo machine. The thermal experiments were conducted using $150 \mu \mathrm{l}$ alumina crucibles loaded with $25 \mathrm{mg}$ of sample. Protective argon gas flowed through the machine at $20 \mathrm{ml} / \mathrm{min}$, with the flow rates of air or argon varied as required. Samples were heated in 50\% air-50\% argon, 25\% air-75\% argon, and $100 \%$ argon mixtures. The calculation of percentage air to argon included the protective argon gas. Because of safety considerations, mixtures of $25 \%$ argon- $75 \%$ air and $100 \%$ air 
could not be used in the Mettler Toledo machine. Instead, samples were heated in $100 \%$ air using a furnace with the same non-isothermal heating conditions, also from room temperature to $900{ }^{\circ} \mathrm{C}$ at $10{ }^{\circ} \mathrm{C} / \mathrm{min}$.

\subsection{In-situ high-temperature synchrotron radiation diffraction (SRD).}

The in-situ crystallization behavior of electrospun titania nanofibers was estimated using nonisothermal high-temperature SRD in $100 \%$ air and $100 \%$ argon from 25 to $900{ }^{\circ} \mathrm{C}$, at 10 ${ }^{\circ} \mathrm{C} / \mathrm{min}$. SRD data were collected at the Australian Synchrotron using the Powder Diffraction Beamline using an Anton Parr HTK 16 hot platinum stage, at a wavelength of $0.1126 \mathrm{~nm}$ and with a fixed incident beam-sample angle of $3^{\circ}$, for $5^{\circ} \leq 2 \theta \leq 84^{\circ}$. The SRD patterns were acquired using a data collection time of 2 min per pattern, at ambient temperature and then in steps of $100{ }^{\circ} \mathrm{C}$, from $200{ }^{\circ} \mathrm{C}$ to $900{ }^{\circ} \mathrm{C}$ [25].

The relative phase levels of crystalline anatase and rutile in 100\% air and $100 \%$ argon were determined from Rietveld analysis using the TOPAS program (Bruker AXS, Version 4.2). Rietveld analysis of the SRD data was also used to estimate oxygen site occupancies for the crystalline anatase and rutile phases.

\subsection{Microstructural imaging}

The structure and morphology of electrospun titania nanofibers prior and following calcination in $100 \%$ air and $100 \%$ argon were studied by field emission scanning electron microscopy (FESEM, Zeiss, Neon, 40EsB, Germany). The samples were coated with a $3 \mathrm{~nm}$ layer of platinum before FESEM imaging to avoid charging. The elemental sample composition was determined by energy dispersive X-ray spectroscopy (EDS). 


\subsection{Band gap}

Band gap assessments were made from absorption spectra recorded using a V-670 UVvisible spectrometer (Jasco, Japan). The main instrument settings were: absorbance photometric mode, a wavelength range from 200 to $750 \mathrm{~nm}$, and a $200 \mathrm{~nm} / \mathrm{min}$ scanning speed. The sample band gap $\left(E_{g}\right)$ was calculated from:

$$
E_{g}=h C / \lambda
$$

where $h$ is Planck's constant $\left(6.626 \times 10^{-34} \mathrm{~J} . \mathrm{s}\right), C$ is the speed of light $\left(3 \times 10^{8} \mathrm{~m} / \mathrm{s}\right)$, and $\lambda$ is the extrapolated wavelength $(\mathrm{nm})$ at which the absorbance value reaches the instrument limit.

\section{Results and discussion}

\subsection{Microstructure imaging}

Fig. 1 shows secondary electron FESEM images of electrospun titania nanofibers recorded at ambient temperature: (a) as-electrospun prior to heating, and after non-isothermal thermal processing from 25 to $900{ }^{\circ} \mathrm{C}$ at $10{ }^{\circ} \mathrm{C} / \mathrm{min}$ in (b) $100 \%$ air and (c) $100 \%$ argon atmospheres. The heated nanofibers have uneven surfaces compared with the as-spun amorphous fibers because of the development of crystalline grains of anatase and rutile [25]. Table 1 shows that the crystalline grains were larger in $100 \%$ argon than in $100 \%$ air, which is consistent with oxygen vacancies created in argon at elevated temperature affecting titania grain growth positively because of enhanced solid state diffusion. Atomic diffusion or the cooperative rearrangement of titania atoms and grain boundary movement during titania phase transformations occurs more easily in $100 \%$ argon than in $100 \%$ air because of the higher mobility of titania atoms in the presence of oxygen vacancies. This can lead to higher grain growth and larger titania grains $[31,32]$. 
The EDS spectrum of the nanofiber sample was recorded after thermal treatment in $100 \%$ argon (Fig. 2). The spectrum is similar to that for as-spun nanofiber (not shown here) besides an absence of the $\mathrm{C}$ peak from loss of organic substance and PVP polymer. The EDS spectrum shows strong $\mathrm{Ti}$ and $\mathrm{O}$ signatures and a weak $\mathrm{Pt}$ signature from the platinum coating on the sample, which are essentially the same when the sample was heated in $100 \%$ air. The complete loss of organic material and PVP polymer from the electrospun titania nanofibers occurred at $\sim 450{ }^{\circ} \mathrm{C}$, see our preliminary results from in-situ high temperature synchrotron radiation diffraction (SRD) (see Fig. 4) and thermal gravimetric analysis (TGA) [10]. The titania nanofibers were initially amorphous by the pronounced amorphous humps in the SRD patterns for $100 \%$ air and $100 \%$ argon, but these humps disappeared by $400{ }^{\circ} \mathrm{C}$. The TGA results showed that the loss of organic material (ethanol and acetic acid) occurred from room temperature to $\sim 150{ }^{\circ} \mathrm{C}$, and the PVP polymer decomposition occurred from $\sim 150$ to $450{ }^{\circ} \mathrm{C}$.

\subsection{Influence of calcining atmosphere on titania colour}

Fig. 3 shows the progressive color change in titania from white after thermal treatment in $100 \%$ air to progressively darker shades of gray after thermal treatment in air-argon compositions from $100 \%$ air to $100 \%$ argon. This color change is attributed to oxygen loss from the titania to form oxygen vacancy defects, and the color intensification is considered to result from an increase in oxygen vacancy concentration with increasing argon concentration. A similar color change effect has been reported by Gamboa et al. [33] in a calcining experiment in which the effect of low levels of chlorine addition to air and argon was studied. This color change was attributed to the formation of oxygen vacancies when heating in argon. 


\subsection{Phase composition results from the SRD}

Figure 4 shows the stacked SRD plots measured in 100\% air and $100 \%$ argon over the temperature range $25-900{ }^{\circ} \mathrm{C}$, and noting that the peaks at $\sim 27.7^{\circ}$ and $35.6^{\circ}$ occur because of the Pt heating holder. Table 2 shows the variation in absolute phase concentrations following SRD for the $100 \%$ argon and $100 \%$ air atmospheres. The presence of oxygen vacancies makes the anatase-to-rutile transformation in $100 \%$ argon more efficient than in $100 \%$ air because some relaxation of the Ti binding environment occurs. Details of absolute levels of amorphous titania and crystalline anatase and rutile at each temperature extracted from the SRD data are given in the preliminary novel study by the authors [10].

\subsection{UV-visible spectral analysis results}

Fig. 5 compares the UV-visible diffuse reflectance spectra of non-calcined as-electrospun nanofibers with those after thermal treatment in the argon-air mixtures followed by cooling to room temperature. The absorption thresholds, band gap, and absorbance were determined from an absorbance versus wavelength graph. The absorbance plots for unheated fibers, and those after heating in 100\%, $50 \%$ air and 25\% air are similar in form. The absorbance falls from $0.7-0.8$ to $\sim 0.1-0.2$ with all showing the expected precipitous drop in absorbance when the photon energy exceeds the band energy gap. A systematic red-shift occurs as the level of argon increases which is consistent with the development of oxygen vacancy levels within the band gap. The red-shift seen here resembles that reported by various authors such as Buha [34] who reported titania thin-film absorbance spectra with different levels of carbon doping, in which an increase in C-doping level increased the magnitude of absorption across the entire visible range. A similar substantial red-shift in absorption of Ag-doped titania nanosquares and Fedoped titania nanoparticles was observed under visible light irradiation [15, 17]. 
The absorbance-wavelength plot for the sample heated in $100 \%$ argon is substantially different from those for the other samples discussed above, with there being a reduced absorbance range, from $c a$. 0.80 to 0.65 , across the wavelength band investigated. This effect is consistent with accounts in the literature that the development of substantial oxygen vacancy defects is responsible for such changes in optical properties. The absorbance change resembles that for C-doped titania thin films for with the absorbance fell from 0.7 to 0.5 over the range $300 \mathrm{~nm}$ to $800 \mathrm{~nm}$ [34]. Following the present study, the measurement of additional absorbance spectra would be required for argon contents of between $75 \%$ and $100 \%$ to reveal the underlying band structure.

\subsection{Influence of calcining atmosphere on band-gap structure}

Fig. 6 shows a plot of band gap versus argon content corresponding to the absorbance spectra in Fig. 5, and Table 2 lists the band gap values for each sample type, and also specifies the sample phase compositions [10, 25, 30]. Table 3 compares band gap results from this study with literature data for titania materials with different forms, mixtures and atmospheric treatment.

The effect on band gap for the as-produced amorphous fiber sample through calcining in $100 \%$ air was to reduce it from the amorphous value of $3.33 \mathrm{eV}$ to $3.09 \mathrm{eV}$, i.e., from within the UV to the visible region. As earlier work on the same sample has indicated that the development of vacancies on heating in air is minimal, the reduction to $3.09 \mathrm{eV}$ is attributed entirely to the development of crystallinity in the fibers - noting the phase levels of about $21 \%$ anatase and $39 \%$ rutile on calcining amorphous material in $100 \%$ air [10]. It is noted that the measured gap value $3.09 \mathrm{eV}$ agrees with the concentration-weighted gap for the two phases: $3.20 \mathrm{eV}$ for pure anatase [5] and $3.03 \mathrm{eV}$ for pure rutile [4, 5]. This appears to be consistent with literature reports of band gaps for mixtures of anatase and rutile [5]. 
Two factors appear to drive the further reduction in band gap as argon is introduced: (i) changes in the titania phase mix, and (ii) the progressive development of oxygen vacancies. The measured gap of $2.18 \mathrm{eV}$ for heating in $100 \%$ argon is related to the titania phase composition (10\% anatase and $63 \%$ rutile) for which the concentration-weighted gap would be $3.05 \mathrm{eV}$ which is $\sim 0.87 \mathrm{eV}$ greater than the measured gap of $2.18 \mathrm{eV}$. The $0.87 \mathrm{eV}$ difference is attributed to oxygen vacancy development. The presence of oxygen vacancies provides more surface active sites and allows for a larger charge carrier density. This is consistent with the electronic structure of titania material being changed by an absent oxygen atom, resulting in the localization of one or two electrons in an oxygen state. The formation of oxygen vacancies results in the formation of unpaired electrons or $\mathrm{Ti}^{3+}$ centers, which form oxygen vacancy states below the conduction band and act as n-type donors $[35,36]$.

The development of oxygen vacancies as the concentration of argon increases was discussed by the authors [10] in terms of non-stoichiometric effects of titania heated in $100 \%$ argon. Oxygen is lost when the sample is heated in argon due to the formation of non-stoichiometric anatase $\left(\mathrm{TiO}_{2-\mathrm{x}}\right)$. This is consistent with the work of Andersson et al. who investigated the composition range of argon-annealed $\mathrm{TiO}_{1.9-2}$ using X-ray powder diffraction [37].

Fig. 7 shows a schematic depicting the assumed band gap states and the apparent influence of oxygen vacancies after calcining to $900{ }^{\circ} \mathrm{C}$ and cooling to room temperature in air-argon mixtures. The introduction of oxygen vacancies in titania results with a presence of localized new oxygen vacancy states existing between the valence (VB) and conduction (CB) bands in the titania band structure. Electrons may be excited from VB to the oxygen vacancy states even under visible light. As the argon level increases from $25 \%$ to $100 \%$, the effective energy gap red-shifts systematically and the sample becomes active in visible light, with the band gap narrowing significantly to $2.94,2.91$, and then $2.18 \mathrm{eV}$ for $50 \%$ air-50\% argon, $25 \%$ air- $75 \%$ argon, and $100 \%$ argon, respectively. Thus, the combined influence of crystallinity 
development and oxygen vacancy formation have extended the light excitation of electrospun titania nanofibers from the UV to well into the visible light range. This has been achieved without chemical doping. Finally, a comparison of band gap results, as shown in Table 3, indicates that the current band gap results are consistent with other data for nano-titania materials reported in the literature.

\section{Conclusions}

This paper focuses on the use of heat treatment of amorphous titania nanofibers, rather than chemical doping, to develop titania photocatalysts that are photoactive in visible light. The results have significance for the development of waste treatment technologies using photocatalytic titania nanofibers which may function in the visible light. The results for heating in different selected air-argon mixtures show that the UV-region band gap found in aselectrospun amorphous nanofibers, $3.33 \mathrm{eV}$, shifted well into the visible region by calcining in air, argon and argon-air mixtures. The band gap value observed for heating in air, $3.09 \mathrm{eV}$, reduces systematically when the material is heated in an air-argon mixture, with the gap for heating in $100 \%$ argon being $2.18 \mathrm{eV}$. The progressive lowering of the band gap is attributed to the development of crystallinity in the fibers as the material is calcined and the associated development of oxygen vacancies when heated in argon.

The narrowed band gap is attributed to the heterostructure titania phases (anatase and rutile) and the formation of oxygen vacancies, which creates a state below the conduction band. Increasing the percentage of argon in the air-argon mixtures reduce the state to below the titania conduction band, which thus increases the oxygen vacancy concentration, and the subsequent band gap narrowing. 


\section{Acknowledgements}

The authors thank the following Curtin University colleagues: Dr. Y. Dong of Mechanical Engineering for access to the electrospinning equipment; Ms. E. Miller of the John de Laeter Centre for assistance with electron microscopy; and Prof. M. Tade, Ms. K. Haynes, and Mr. A. Chan of Chemical Engineering for access to the TGA/DSC Mettler Toledo and UV-Visible spectrometer instruments. 


\section{References}

[1] T. Potlog, P. Dumitriu, M. Dobromir, A. Manole, D. Luca, Nb-doped $\mathrm{TiO}_{2}$ thin films for photovoltaic applications, Mater. Des. 85 (2015) 558-563.

[2] D. Wu, M. Long, Realizing visible-light-induced self-cleaning property of cotton through coating $\mathrm{N}_{-} \mathrm{TiO}_{2}$ film and loading AgI particles, ACS. Appl. Mater. Interfaces 3 (2011) 47704774.

[3] K. Eufinger, D. Poelman, H. Poelman, R. D. Gryse, G. B. Marin, Photocatalytic activity of dc magnetron sputter deposited amorphous $\mathrm{TiO}_{2}$ thin films, Appl. Surf. Sci. 254 (2007) 148152.

[4] H. Tang, K. Prasad, R. Sanjines, P. E. Schmid, F. Levy, Electrical and optical properties of $\mathrm{TiO}_{2}$ anatase thin films, J. Appl. Phys. 75 (1994) 2042-2047.

[5] D. O. Scanlon, C. W. Dunnill, J. Buckeridge, S. A. Shevlin, A. J. Logsdail, S. M. Woodley, C. R. Catlow, M. J. Powell, R. G. Palgrave, I. P. Parkin, G. W. Watson, T. W. Keal, P. Sherwood, A. Walsh, A. A. Sokol, Band alignment of rutile and anatase $\mathrm{TiO}_{2}$, Nat. Mater. 12 (2013) 798-801.

[6] A. Natoli, A. Cabeza, A. G. Torre, M. A. Aranda, I. Santacruz, Colloidal processing of macroporous $\mathrm{TiO}_{2}$ materials for photocatalytic water treatment, J. Am. Ceram. Soc. 95 (2012) 502-508.

[7] S. Kment, P. Kluson, V. Stranak, P. Virostko, J. Krysa, M. Cada, J. Pracharova, M. Kohout, M. Morozova, P. Adamek, Z. Hubicka, Photo-induced electrochemical functionality of the $\mathrm{TiO}_{2}$ nanoscale films, Electrochim. Acta 54 (2009) 3352-3359.

[8] H. Li, W. Zhang, W. Pan, Enhanced photocatalytic activity of electrospun $\mathrm{TiO}_{2}$ nanofibers with optimal anatase/rutile ratio, J. Am. Ceram. Soc. 94 (2011) 3184-3187.

[9] B. Ohtani, O. O. Mahaney, D. Li, R. Abe, What is degussa (evonik) P25? crystalline composition analysis, reconstruction from isolated pure particles and photocatalytic activity test, J. Photochem. Photobiol., A: Chem. 216 (2010) 179-182.

[10] H. Albetran, B. H O'Connor, I. M. Low, Activation energies for phase transformations in electrospun titania nanofibers: comparing the influence of argon and air atmospheres, Appl. Phys. A In press.

[11] S. W. Hsu, T. S. Yang, T. K. Chen, M. S. Wong, Ion-assisted electron-beam evaporation of carbon-doped titanium oxide films as visible-light photocatalyst, Thin Solid Films 515 (2007) 3521-3526. 
[12] J. Yi, X. Yuan, H. Wang, H. Yu, F. Peng, Preparation of $\mathrm{Bi}_{2} \mathrm{Ti}_{2} \mathrm{O}_{7} / \mathrm{TiO}_{2}$ nanocomposites and their photocatalytic performance under visible light irradiation, Mater. Des. 86 (2015) 152155.

[13] V. J. Babu, A. S. Nair, Z. Peining, S. Ramakrishna, Synthesis and characterization of rice grains like nitrogen-doped $\mathrm{TiO}_{2}$ nanostructures by electrospinning-photocatalysis, Mater. Lett. 65 (2011) 3064-3068.

[14] A. Ghicov, J. M. Macak, H. Tsuchiya, J. Kunze, V. Haeublein, L. Frey, P. Schmuki, Ion implantation and annealing for an efficient N-doping of $\mathrm{TiO}_{2}$ nanotubes, Nano. Lett. 6 (2006) 1080-1082.

[15] C. Yu, L. Wei, X. Li, J. Chen, Q. Fan, J.C. Yu, Synthesis and characterization of Ag/TiO $2^{-}$ B nanosquares with high photocatalytic activity under visible light irradiation, Mater. Sci. Eng. B 178 (2013) 344-348.

[16] M. Takeuchi, H. Yamashita, M. Matsuoka, M. Anpo, T. Hirao, N. Itoh, N. Iwamoto, Photocatalytic decomposition of No under visible light irradiation on the Cr-ion-implanted $\mathrm{TiO}_{2}$ thin film photocatalyst, Catal. Lett. 67 (2000) 135-137.

[17] S. K. Patel, S. Kurian, N.S. Gajbhiye, Room-temperature ferromagnetism of Fe-doped $\mathrm{TiO}_{2}$ nanoparticles driven by oxygen vacancy, Mater. Res. Bull. 48 (2013) 655-660.

[18] D. Li, N. Ohashi, S. Hishita, T. Kolodiazhnyi, H. Haneda, Origin of visible-light-driven photocatalysis: a comparative study on N/F-doped and $\mathrm{N}-\mathrm{F}$-codoped $\mathrm{TiO}_{2}$ powders by means of experimental characterizations and theoretical calculations, J. Solid. State. Chem. 178 (2005) 3293-3302.

[19] R. P. Antony, T. Mathews, P. K. Ajikumar, D. N. Krishna, S. Dash, A. K. Tyagi, Electrochemically synthesized visible light absorbing vertically aligned $\mathrm{N}$-doped $\mathrm{TiO}_{2}$ nanotube array films, Mater. Res. Bull. 4 (2012) 4491-4497.

[20] J. H. Huang, M. S. Wong, Structures and properties of titania thin films annealed under different atmosphere, Thin Solid Films 520 (2011) 1379-1384.

[21] A. Ghicov, H. Tsuchiya, J. M. Macak, P. Schmuki, Annealing effects on the photoresponse of $\mathrm{TiO}_{2}$ nanotubes, Physica. Status. Solidi. A 203 (2006) 28-30.

[22] Q. Wu, R. V. Krol, Selective photoreduction of nitric oxide to nitrogen by nanostructured $\mathrm{TiO}_{2}$ photocatalysts: role of oxygen vacancies and iron dopant, J. Am. Chem. Soc. 134 (2012) 9369-9375.

[23] J. Y. Park, J. J. Yun, C. H. Hwang, I. H. Lee, Influence of silver doping on the phase transformation and crystallite growth of electrospun $\mathrm{TiO}_{2}$ nanofibers, Mater. Lett. 64 (2010) 2692-2695. 
[24] I. M. Low, F. K. Yam, W. K. Pang, In-situ diffraction studies on the crystallization and crystal growth in anodized $\mathrm{TiO}_{2}$ nanofibres, Mater. Lett. 87 (2012) 150-152.

[25] H. Albetran, H. Haroosh, Y. Dong, V. M. Prida, B. H. O’Connor, I. M. Low, Phase transformations and crystallization kinetics in electrospun $\mathrm{TiO}_{2}$ nanofibers in air and argon atmospheres, Appl. Phys. A 116 (2014) 161-169.

[26] Q. Li, D. J. G. Satur, H. Kim, H. G. Kim, Preparation of sol-gel modified electrospun $\mathrm{TiO}_{2}$ nanofibers for improved photocatalytic decomposition of ethylene, Mater. Lett. 76 (2012) $169-172$.

[27] H. Li, W. Zhang, B. Li, W. Pan, Diameter-dependent photocatalytic activity of electrospun $\mathrm{TiO}_{2}$ nanofiber, J. Am. Ceram. Soc. 93 (2010) 2503-2506.

[28] S. Chuangchote, J. Jitputti, T. Sagawa, S. Yoshikawa, Photocatalytic activity for hydrogen evolution of electrospun $\mathrm{TiO}_{2}$ nanofibers, ACS. Appl. Mater. Interfaces 1 (2009) 11401143.

[29] R. Chandrasekar, L. Zhang, J. Y. Howe, N. E. Hedin, Y. Zhang, H. Fong, Fabrication and characterization of electrospun titania nanofibers, J. Mater. Sci. 44 (2009) 1198-1205.

[30] H. Albetran, B. H O'Connor, I. M. Low, Effect of vanadium ion implantation on the crystallization kinetics and phase transformation of electrospun $\mathrm{TiO}_{2}$ nanofibers, Appl. Phys. A 120 (2015) 623-634.

[31] Y. Iida, S. Ozaki, Grain growth and phase transformation of titanium oxide during calcination, J. Am. Ceram. Soc. 44 (1961) 120-127.

[32] X. Ding, X. Liu, Correlation between anatase-to-rutile transformation and grain growth in nanocrystalline titania powders, J. Mater. Res. 13 (1998) 2556-2559.

[33] J. A. Gamboa, D. M. Pasquevich, Effect of chlorine atmosphere on the anatase-rutile transformation, J. Am. Ceram. Soc. 75 (1992) 2934-2938.

[34] J. Buha, solar absorption and microstructure of C-doped and $\mathrm{H}$-co-doped $\mathrm{TiO}_{2}$ thin films, J. Phys. D: Appl. Phys. 45 (2012) 385305.

[35] I. Nakamura, N. Negishi, S. Kutsuna, T. Ihara, S. Sugihara, K. Takeuchi, role of oxygen vacancy in the plasma-treated $\mathrm{TiO}_{2}$ photocatalyst with visible light activity for No removal, J. Mole. Cataly. A: Chem. 161 (2000) 205-212.

[36] H. Seo, L. R. Baker, A. Hervier, J. Kim, J. Whitten, G. A. Somorjai, Generation of highly n-type titanium oxide using plasma fluorine insertion, Nano. Lett. 11 (2010) 751-756.

[37] S. Andersson, B. Collen, U. Kuylenstierna, A. Magneli, Phase analysis studies on the titanium-oxygen system, Acta. Chem. Scand. 11 (1957) 1641-1652. 
[38] D. Chen, Z. Jiang, J. Geng, Q. Wang, D. Yang, Carbon and nitrogen Co-doped $\mathrm{TiO}_{2}$ with enhanced visible-light photocatalytic activity, Ind. Eng. Chem. Res. 46 (2007) 2741-2746.

[39] O. Rosseler, M. V Shankar, M. K. Du, L. Schmidlin, N. Keller, V. Keller, Solar light photocatalytic hydrogen production from water over $\mathrm{Pt}$ and $\mathrm{Au} / \mathrm{TiO}_{2}$ (anatase/rutile) photocatalysts: influence of noble metal and porogen promotion, J. Catal. 269 (2010) 179190.

[40] D. Reyes-Coronado, G. Rodriguez-Gattorno, M. E. Espinosa-Pesqueira, C. Cab, R. de Coss, G. Oskam, Phase-pure $\mathrm{TiO}_{2}$ nanoparticles: anatase, brookite and rutile, Nanotechnology 19 (2008) 145605. 


\section{Tables}

\section{Table 1}

Nanofiber and grain size measurements. The \pm symbol refers to the size range for size assessment. The number of measurements for each entry was 40 .

\begin{tabular}{ccc}
\hline Calcination Conditions & $\begin{array}{c}\text { Nanofiber size } \\
(\mathrm{nm})\end{array}$ & $\begin{array}{c}\text { Grain size } \\
(\mathrm{nm})\end{array}$ \\
\hline As-Spun (Not Calcined) & $665 \pm 330$ & Amorphous \\
100\% Air & $351 \pm 145$ & $21 \pm 5$ \\
$100 \%$ Argon & $328 \pm 113$ & $118 \pm 49$ \\
\hline
\end{tabular}

\section{Table 2}

Phase compositions and band gaps for titania nanofibers at room temperature after calcining to $900{ }^{\circ} \mathrm{C}$ in $100 \%$ air, $100 \%$ argon, and air-argon mixtures.

\begin{tabular}{cccccc}
\hline Calcination Conditions & $\begin{array}{c}\text { Amorphous } \\
(\%)\end{array}$ & $\begin{array}{c}\text { Anatase } \\
(\%)\end{array}$ & $\begin{array}{c}\text { Rutile } \\
(\%)\end{array}$ & $\begin{array}{c}\text { Crystallinity } \\
(\%)\end{array}$ & $\begin{array}{c}\text { Band Gap } \\
(\mathrm{eV})\end{array}$ \\
\hline As-spun (Not Calcined) & 100 & 0 & 0 & 0 & 3.33 \\
100\% Air & 40.5 & 20.9 & 38.6 & 59.5 & 3.09 \\
$50 \%$ Air-50\% Argon & NA* $^{*}$ & NA* $^{*}$ & NA* $^{*}$ & NA* $^{*}$ & 2.94 \\
25\% Air-75\% Argon & NA $^{*}$ & NA* & NA* & NA* & 2.91 \\
$100 \%$ Argon & 26.6 & 10.3 & 63.1 & 73.4 & 2.18 \\
\hline
\end{tabular}

*Not available 


\section{Table 3}

Comparison of band gap results from present study with data from literature for titania materials.

\begin{tabular}{|c|c|c|c|c|c|}
\hline Study & $\begin{array}{l}\text { Titania } \\
\text { Nano- } \\
\text { material }\end{array}$ & Treatment & $\begin{array}{l}\text { Band } \\
\text { Gap } \\
(\mathrm{eV})\end{array}$ & Am: A: R & Comment \\
\hline This Study & Fiber & $\begin{array}{l}\text { As-spun } \\
100 \% \text { Air } \\
100 \% \text { Argon }\end{array}$ & $\begin{array}{l}3.33 \\
3.09 \\
2.18\end{array}$ & $\begin{array}{l}\text { 100:0:0 } \\
\text { 40: } 21: 39 \\
\text { 27: } 10: 63\end{array}$ & Presence of oxygen vacancies \\
\hline $\begin{array}{c}\text { Potlog et al. } \\
\text { [1] }\end{array}$ & Films & $\begin{array}{l}\text { Vacuum } \\
100 \% \mathrm{H}_{2}\end{array}$ & $\begin{array}{l}3.34 \\
3.22\end{array}$ & $\begin{array}{c}0: 62: 38 \\
0: 100: 0\end{array}$ & \\
\hline $\begin{array}{c}\text { Tang et al. } \\
\text { [4] }\end{array}$ & Films & Argon \& $\mathrm{O}_{2}$ & $\begin{array}{l}3.20 \\
3.00 \\
\end{array}$ & $\begin{array}{l}\text { 0: } 100: 0 \\
0: 0: 100\end{array}$ & \\
\hline $\begin{array}{l}\text { Chen et al. } \\
\text { [38] }\end{array}$ & Powder & $100 \%$ Air & 3.15 & 0: 100: 0 & \\
\hline $\begin{array}{c}\text { Rosseler et al. } \\
\text { [39] }\end{array}$ & $\begin{array}{l}\text { Sol-gel } \\
\text { promoted } \\
\text { template }\end{array}$ & $100 \%$ Air & $\begin{array}{l}3.02 \\
2.99 \\
2.97 \\
2.94\end{array}$ & $\begin{array}{l}0: 50: 50 \\
0: 40: 60 \\
0: 30: 70 \\
0: 5: 95\end{array}$ & $\begin{array}{c}\mathrm{TiO}_{2}-\text { polyoxyethylene cetylether } \\
\mathrm{TiO}_{2}-\mathrm{CTAB} \\
\mathrm{TiO}_{2}-\text { polyvinyl alcohol } \\
\mathrm{TiO}_{2} \text { - polyethylene glycol }\end{array}$ \\
\hline $\begin{array}{c}\text { Coronado et al. } \\
{[40]}\end{array}$ & Particles & $100 \%$ Air & $\begin{array}{l}3.21 \\
3.00\end{array}$ & $\begin{array}{l}\text { 0: } 100: 0 \\
0: 0: 100\end{array}$ & \\
\hline
\end{tabular}

Am: amorphous, A: anatase, and R: rutile 


\section{Figure captions}

1. Secondary electron FESEM micrographs of electrospun titania nanofibers recorded at ambient temperature: (a) as-electrospun prior to heating, and after non-isothermal heating from $25{ }^{\circ} \mathrm{C}$ to $900{ }^{\circ} \mathrm{C}$ at $10{ }^{\circ} \mathrm{C} / \mathrm{min}(\mathrm{b})$ in $100 \%$ air, and (c) in $100 \%$ argon atmospheres.

2. EDS spectrum of electrospun titania nanofibers recorded at ambient temperature after heating from $25{ }^{\circ} \mathrm{C}$ to $900{ }^{\circ} \mathrm{C}$ at $10{ }^{\circ} \mathrm{C} / \mathrm{min}$ in $100 \%$ argon.

3. Color changes in electrospun titania nanofibrous material observed at room temperature following non-isothermal heating from $25{ }^{\circ} \mathrm{C}$ to $900{ }^{\circ} \mathrm{C}$ at $10{ }^{\circ} \mathrm{C} / \mathrm{min}$ in argon-air mixtures.

4. UV-visible spectra for as-electrospun titania nanofibrous material after non-isothermal heating from $25{ }^{\circ} \mathrm{C}$ to $900{ }^{\circ} \mathrm{C}$ at $10{ }^{\circ} \mathrm{C} / \mathrm{min}$ in $100 \%$ air, $50 \%$ air-50\% argon, $25 \%$ air- $-75 \%$ argon and $100 \%$ argon, and then cooling to room temperature.

5. Band gap values of as-electrospun titania nanofibrous material, extracted from UV-visible spectra in Fig. 4. Band gaps in $\mathrm{eV}$ at room temperature following non-isothermal heating from $25{ }^{\circ} \mathrm{C}$ to $900{ }^{\circ} \mathrm{C}$ at $10{ }^{\circ} \mathrm{C} / \mathrm{min}$ in air-argon mixtures, and then colling to room temperature.

6. Stacked SRD plots for electrospun titania nanofibers material when heated in $100 \%$ air and in $100 \%$ argon, from 25 to $900^{\circ} \mathrm{C}$. [A: anatase, R: rutile, Pt: platinum]. Plots taken from Albetran et al. [25].

7. Band gap states and the assumed influence of oxygen vacancies with change in air-argon mix. Argon (\%) in air-argon mixtures [Legend: $\mathrm{CB}=$ Conduction band, $\mathrm{VB}=$ Valence band]. 